IZA DP No. 8206

The Length of Maternity Leave and Family Health

Louise Voldby Beuchert

Maria Knoth Humlum

Rune Vejlin

May 2014

Forschungsinstitut zur Zukunft der Arbeit Institute for the Study of Labor 


\title{
The Length of Maternity Leave and Family Health
}

\author{
Louise Voldby Beuchert \\ Aarhus University \\ Maria Knoth Humlum \\ Aarhus University \\ and IZA \\ Rune Vejlin \\ $C A P$, Aarhus University
}
Discussion Paper No. 8206
May 2014

\author{
IZA \\ P.O. Box 7240 \\ 53072 Bonn \\ Germany \\ Phone: +49-228-3894-0 \\ Fax: +49-228-3894-180 \\ E-mail: iza@iza.org
}

\begin{abstract}
Any opinions expressed here are those of the author(s) and not those of IZA. Research published in this series may include views on policy, but the institute itself takes no institutional policy positions. The IZA research network is committed to the IZA Guiding Principles of Research Integrity.

The Institute for the Study of Labor (IZA) in Bonn is a local and virtual international research center and a place of communication between science, politics and business. IZA is an independent nonprofit organization supported by Deutsche Post Foundation. The center is associated with the University of Bonn and offers a stimulating research environment through its international network, workshops and conferences, data service, project support, research visits and doctoral program. IZA engages in (i) original and internationally competitive research in all fields of labor economics, (ii) development of policy concepts, and (iii) dissemination of research results and concepts to the interested public.
\end{abstract}

IZA Discussion Papers often represent preliminary work and are circulated to encourage discussion. Citation of such a paper should account for its provisional character. A revised version may be available directly from the author. 


\section{ABSTRACT}

\section{The Length of Maternity Leave and Family Health*}

We study the relationship between the length of maternity leave and the physical and psychological health of the family. Using a reform of the parental leave scheme in Denmark that increased the number of weeks of leave with full benefit compensation, we estimate the effect of the length of maternity leave on a range of health indicators including the number of hospital admissions for both mother and child and the probability of the mother receiving antidepressants. The reform led to an increase in average post-birth maternity leave of 32 days. We find limited evidence that the increase in the length of maternity leave matters for child or maternal health outcomes and thus we complement the existing evidence on maternity leave expansions that tends to find limited effects on children's later developmental, educational, and labor market outcomes. Our results suggest that any beneficial effects of increasing the length of maternity leave are greater for low-resource families.

JEL Classification: I18, J13, J18

Keywords: maternity leave, family health, regression-discontinuity

Corresponding author:

Rune Vejlin

Department of Economics and Business

Aarhus University

Fuglesangs Allé 4

8210 Aarhus V

Denmark

E-mail: rvejlin@econ.au.dk

\footnotetext{
${ }^{*}$ We thank Helena Skyt Nielsen for sharing her programs for computation of leave. We thank Mette Escherich Østergaard for excellent and thorough research assistance. Finally, we are thankful for constructive comments and suggestions from participants at the ESPE 2012 conference and the DGPE 2013 workshop.
} 


\section{Introduction}

By nature mother and child have a symbiotic relationship. However, the link between mother and child is no longer as necessary from a practical standpoint, since relatively good alternatives to breastfeeding and maternal care generally exist in developed countries. In spite of this development-or maybe because of it - the amount of time a mother spends with her child versus on the labor market is a source of much debate, and the effects hereof the subject of extensive research. In this paper, we investigate the short-term effect of increasing the length of maternity leave on family health. Maternity leave expansions are argued to have beneficial effects on everything from the length of breastfeeding to the cognitive ability of the child. While existing studies have found compelling evidence that increases in maternity leave increase the extent of breastfeeding, see e.g. Baker and Milligan (2008b), and affect women's labor market behavior, see e.g. Lalive and Zweimüller (2009), there has been little evidence suggesting other substantial effects.

Several existing empirical studies have used policy reforms to estimate the effect of maternity leave on short- and long-term outcomes of children. Most of the literature on long-term outcomes has focused on scholastic performance and labor market outcomes of the child. Dustmann and Schönberg (2012) rule out any large gains from increases in maternity leave in terms of higher high school attendance and higher wages using German data. Using Danish data, Rasmussen (2010) also finds no effect on children's long-term educational outcomes. Liu and Skans (2010) use a reform in Sweden that extended the maternity leave benefit period from 12 to 15 months. They find no beneficial effects on children's scholastic performance. Dahl, Løken, Mogstad, and Salvanes (2013) consider a series of reforms in Norway that expanded paid maternity leave. They consider a range of outcomes and find no effects on either children's school outcomes, parental earnings, participation in the labor market, completed fertility, marriage or divorce. Generally, little evidence exists that increasing maternity leave has substantial long-term effects on children. 
There is limited evidence of the effect of maternity leave on short-term health outcomes. Baker and Milligan (2008b) estimate the effect of a reform of maternity leave in Canada that caused mothers to increase the time before they returned to work after giving birth by 3-3.5 months from a level of around 1 month. They use a 6-year window around the reform and find significant effects on the duration of breastfeeding and some evidence of beneficial effects on child health at age 7-12 months. However, these effects do not persist into older ages. Baker and Milligan (2008a) use the same reform. They first document that the increased maternity leave crowded out home-based care by unlicensed non-relatives. They find almost no effects on indicators for child development such as family environment and motor-social development. Rossin (2011) uses a reform (The Family and Medical Leave Act) in the US in 1993 which mandated that new mothers were to receive 12 weeks of unpaid leave with guaranteed health insurance coverage. ${ }^{1}$ She finds that the reform had positive effects on child health in the form of increases in birth weight, decreases in the likelihood of a premature birth, and substantial decreases in infant mortality for children of college-educated and married mothers. A recent review on mechanism and policies by Björklund and Salvanes (2011) concludes that the research on maternity leave and health is inconclusive. They especially point out that research on the short-term effects on child health is rare and that this should be the subject of further investigation.

In the child development literature, it is emphasized how early investments are important for and complementary to later childhood investments. From this perspective, it is important to investigate whether the time a mother spends with her child has effects on e.g. the child's accumulation of human and health capital. In light of the existing evidence on long-run effects of maternity leave expansions, it is of interest to further investigate the short-run effects of maternity leave expansions. Maternity leave schemes can be viewed as policies that improve family resources and investments. Increasing the length of maternity leave is expected to improve the possibilities of the mother to invest more resources in the well-being of herself and her newborn. This may be by increasing the actual

\footnotetext{
${ }^{1}$ Women were free to take the leave during their pregnancy and/or after childbirth.
} 
amount of time spent with the child or indirectly by improving the time allocation within the family. For example, if a mother is given more time to cope with her new role as a mother, it may also indirectly improve the quality of the time spent with the child. In this line of thinking, increasing the length of maternity leave may affect not only the health of the child, but also the physical and mental health of the mother. Children whose mothers take longer maternity leave may also get higher quality care in the first years of life, for example in the form of prolonged breastfeeding ${ }^{2}$, more adult supervision and interaction, a stronger sense of community between mother and child, and are likely to be less exposed to infections that are common in publicly provided childcare where children interact more with other children. Given that the length of maternity leave potentially has important implications for child and maternal health, it may also affect more general family well-being and family decisions like fertility and divorce.

To investigate the effects of the length of maternity leave on family health and well-being, we employ an identification strategy based on a reform of the Danish maternity leave scheme that changed the choice set and economic incentives for mothers' leave-taking. As a consequence of the reform, mothers on average increased the length of their maternity leave by about 32 days. We contribute to a scarce literature on short-term health effects of maternity leave. Since we have access to administrative data on the entire Danish population and exact birth dates, we can employ an instrumental variables strategy that uses the fact that the length of maternity leave jumps discontinuously at the date of implementation of the reform. The identification strategy is similar to those of many of the existing studies, but e.g. compared to Baker and Milligan (2008b) who consider a window of 6 years around the reform, we have the advantage of data that allows for a narrow window (60 days) around the reform date. This poten-

\footnotetext{
${ }^{2}$ For example, the World Health Organization, the US Department of Health and Human Services, National Board of Health in Denmark, and Health Canada have extended exclusive breastfeeding advisories to 6 months, and recommendations for continued feeding up to 2 years. A guide for Danish health care personnel, Sundhedsstyrelsen (2008), mentions various areas where breastfeeding has potential benefits including growth, the central nervous system, immune-related effects, mortality, lifestyle diseases, and necrotizing enterocolitis. Potential benefits for the mother are related to: weight loss, type 2 diabetes, cancer, and postpartum reactions.
} 
tially reduces selecton bias and increases validity. We focus on a wide range of health outcomes for mothers (number of hospital admissions, being hospitalized with depression, and receiving antidepressants) and children (number of hospital admissions, number of emergency department visits). We also consider potential effects on parental relationship dissolution and having an additional child. Since we consider outcomes measured 1-5 years after birth, we are looking at a different margin than the other studies mentioned above which tend to focus on outcomes measured within a year after birth.

In line with most of the literature on long-term outcomes, we find limited effects of increasing the length of maternity leave on short-term health outcomes of the mother and child. However, we do find weak evidence that increasing maternity leave decreases the number of admissions for the mother in the very short run. In addition, we show that there is some heterogeneity in the responses of mothers to the increase in the length of maternity leave suggesting that if there are any beneficial effects of increasing the length of maternity leave, then they are higher for low-resource families.

The structure of the paper is as follows. The institutional settings regarding maternity leave and the specific reform we use as part of our identification strategy are described in section 2. In section 3, we describe our empirical approach. Section 4 describes the data used, and in section 5 we present the estimation results. Section 6 concludes.

\section{Maternity Leave and Benefits in Denmark}

Denmark has a strong tradition for generous family-friendly policies. Women who are attached to the labor market ${ }^{3}$ are entitled to benefits while on maternity leave. ${ }^{4}$ Over the past 30 years the benefit period has been gradually expanded and the flexibility of the leave schemes has increased. We will focus on a rather

\footnotetext{
${ }^{3}$ Being attached to the labor market means being either employed or unemployed with unemployment insurance.

${ }^{4}$ We think of maternity leave in a broad sense as encompassing the mother's post-birth leave and later child-related leave spells that may or may not be consecutive. We allow maternity leave to be taken from childbirth and until the child turns 2 .
} 
large expansion of the leave scheme which was implemented in the beginning of 2002. Prior to the reform, new mothers were entitled to full benefit compensation for 24 weeks and reduced benefit compensation (60 percent) for 52 weeks. With the implementation of the reform, new mothers became entitled to 46 weeks of full benefit compensation. ${ }^{5}$ This changed the economic incentives for leavetaking fundamentally. Table 1 provides a rough overview of the benefit rules before and after the reform. ${ }^{6}$

Table 2 gives an overview of the implementation of the reform. The date of commencement for the new benefit rules was 27 March, 2002. For all mothers giving birth on or after this date the new benefit rules apply. However, mothers giving birth on 1 January, 2002, to 26 March, 2002, were given the option of choosing their preferred set of benefit rules (pre-reform or post-reform rules). It turned out that the vast majority of women chose that their maternity leave should be governed by the post-reform rules. Figure 1 shows the average length of maternity leave for women giving birth from 1 July, 2001, to 1 July, 2002. We see that the average length of leave jumps on 1 January, but is unchanged on 27 March. This corroborates the view that almost all women chose the post-reform benefit rules if given the option to choose.

The reform also affected fathers' incentives for leave-taking. However, since the average length of paternity leave increased by about 0.25 days from a level of 15 days (1.6 percent increase) and the average length of maternity leave increased by about 32 days from a level of 244 days (12 percent increase), we assume that any changes in family health are caused by the increase in the length of maternity leave. ${ }^{7}$ We will briefly return to this issue in the estimation section, where we include paternity leave as an additional control to check the robustness of our results.

\footnotetext{
${ }^{5}$ The reform changed the benefit entitlements, but many employers provide additional compensation for new mothers.

${ }^{6}$ In reality the changes were more complex than what is described in the text. Generally, the reform extended the period with full benefit compensation and increased flexibility in leavetaking. The increased flexibility came in the shape of a larger part of the leave period being potentially shared with the father and the possibility of postponing part of the maternity leave.

${ }^{7}$ Nielsen (2009) uses the same reform and a difference-in-differences strategy to estimate the effect of the changed economic incentives on intra-household leave-sharing.
} 


\section{Empirical Approach}

In order to estimate the causal relationship between the length of maternity leave and the subsequent health of the family, we take advantage of the reform of the benefit rules described above. More explicitly, we will use the fact that the implementation of the reform was very speedy so no self-selection was possible. Prior to the reform, maternity leave first became a hot topic in the November 2001 election campaign and the reform was passed by the new government on 20 March, 2002, only a couple of months later. Recall, that the average length of maternity leave jumps discontinuously on 1 January, cf. Figure 1. We will use an instrumental variables (IV) strategy based on this fact.

\subsection{Instrumental Variables}

We are interested in estimating the impact of the number of days spent on maternity leave on family health outcomes, e.g. the number of hospital admissions. Using Ordinary Least Squares (OLS) to consistently estimate this relationship would require the assumption that the error term and the number of days spent on maternity leave are uncorrelated. In addition to institutional constraints, the length of maternity leave is likely to be affected by the mother's (and the father's) preferences for spending time with her (his) children, the economic circumstances of the family, and many other factors which can be controlled in varying degrees. Since we are unlikely to be able to capture all of these factors with the data available to us, we choose to instrument the length of maternity leave.

The IV strategy is based on the regression discontinuity that arises due to the implementation of the reform. It is common to use discontinuities as the foundation of an IV strategy, see e.g. Angrist and Lavy (1999). The instrument is an indicator variable for whether the mother gave birth prior to or after 1 January defined as follows

$$
T_{i}=1\left[d_{i} \geq d_{0}\right]
$$

where $d_{i}$ is the distance (in days) from 1 January, 2002, to the date of childbirth 
for woman $i$ and $d_{0}=0$. Thus, for women giving birth 1 January or later, $T_{i}=1$. We can think of women who gave birth on 1 January or later as being in the treatment group, and women giving birth before 1 January as being in the control group. We estimate the following equation using two-stage least squares:

$$
y_{i}=\alpha+\delta L_{i}+f\left(d_{i}\right)+\boldsymbol{X}_{\boldsymbol{i}} \boldsymbol{\beta}+\epsilon_{i}
$$

where $y_{i}$ is the outcome for woman $i$ or child $i, L_{i}$ is the length of maternity leave (in days), $f(\cdot)$ is a potentially flexible function of distance, $d_{i}$, and $\boldsymbol{X}_{i}$ is a vector of observed covariates including child, mother, and father characteristics. In order to obtain a consistent estimate of $\delta$, we instrument $L_{i}$ with $T_{i}$.

The identification strategy requires that the length of maternity leave jumps discontinuously at $d_{0}$ and additionally that the outcome of interest would have been a smooth function of date of childbirth around $d_{0}$ in the absence of a change in benefit rules. ${ }^{8}$ Generally, there is no reason to suspect that mothers who give birth (or children who are born) a few days apart are substantially different. Some studies find evidence of systematic differences in maternal characteristics and child outcomes across season of birth, e.g. Bound and Jaeger (1996) and Buckles and Hungerman (2013), but like Humlum and Vejlin (2013) we do not find this to be a problem when using an estimation strategy that compares mothers giving birth (or children who are born) within the same season. Later, we will present evidence that the treatment and control groups do not differ in terms of observable characteristics.

\subsection{Interpreting the Effects}

In the case of heterogeneity in responses to treatment, the parameter of interest, $\delta$, can be given a local average treatment effect (LATE) interpretation. $\delta$ captures the effect of increasing the length of maternity leave by one day for the mothers who would take longer maternity leaves after the reform than they would have

\footnotetext{
${ }^{8}$ This limits some of the outcomes that we are able to study. For example, we cannot study primary school enrollment, since the school starting age rules in Denmark stipulate that children should enroll in school in the year they turn 6 .
} 
done before the reform. Actually, since we have a binary instrument and variable treatment intensity (days of maternity leave), 2SLS identifies a weighted average of per-unit average causal effects for those mothers who changed the length of their leave due to the reform, see Angrist and Imbens (1995). Although it is pretty clear that the vast majority of mothers opt for the new benefit rules when given a choice, it is not entirely clear how this translates into changes in the length of leave for each mother. E.g. some mothers may increase the length of leave by 2 weeks, others by 6 weeks etc. However, to get an idea of the aggregate effect of the reform, we can multiply $\delta$ with the average increase in the length of maternity leave. If we assume that all women 'comply' with the reform and increase the length of their maternity leave, we still would not be able to identify the average effect of an additional day of leave in the population since benefit rules only apply for the about 74 percent of new mothers who are either employed or unemployed with unemployment insurance. The remaining 26 percent of new mothers are not entitled to benefits. ${ }^{9}$ Thus, the estimation sample we will use will be a selected sample of those strongly attached to the labor market. However, they still represent a majority of the population of mothers.

One possible threat to identification of LATE is that the monotonicity assumption does not hold. In our application, monotonicity requires that there are no mothers who choose shorter leave spells in the post-reform regime than they would have chosen in the pre-reform regime. To address this concern, we take a closer look at the pre- and post-reform rules described in section 2. In Table 3 , we show the take-up of the different components of parental leave in the two regimes. With the pre-reform rules each parent may supplement parental leave with up to 52 weeks of childcare leave at a reduced benefit rate corresponding to 60 percent of the unemployment benefit rate. ${ }^{10}$ The purpose is for parents to have the possibility of taking leave later in the child's life. A similar option

\footnotetext{
${ }^{9}$ Of these, 26 percent are on social assistance, 8 percent are under education, 5 percent are unemployed but neither on social assistance nor unemployment benefits. In addition, information is missing for about 30 percent of these individuals. These are most likely immigrants.

${ }^{10}$ More precisely childcare leave consists of two parts. First, the parent has the right to take 8-13 weeks of childcare leave, and up to 26 weeks if the leave spell starts before the child turns 1 year old ("retsbaseret orlov"). Second, there is a possibility of taking up to a total of 52 weeks of childcare leave conditional on the employer's acceptance ("aftalebaseret orlov").
} 
exists after the reform where parents can postpone part of the leave. With the post-reform rules the mother also have a possibility of extending the total leave period to up to 60 weeks at a reduced benefit rate. All in all, it is not clear that all mothers would choose a longer leave spell after the reform. Table 3 shows that 7 percent of the mothers are defiers in the sense that they actually choose a longer leave spell before the reform than what would be possible after the reform. Notice however, that the 7 percent is an absolute upper limit, since the reform increases the possibility financially, through higher paid leave, to take unpaid leave after the paid leave has ended, which is not registered. Although the 7 percent is relatively small, this constitutes a likely violation of the monotonicity assumption which should be kept in mind when giving the estimates a LATE interpretation.

New mothers who are entitled to benefits tend to be younger, better educated, and in general to have better socioeconomic characteristics. If we expect parents and children from low-resource families to be more vulnerable to interventions affecting the time mother and child spends together, we would expect our estimates of the effect of the length of maternity leave to be a conservative estimate of the average effect in the population.

\section{Data}

We take advantage of several administrative data sets covering the entire Danish population. We focus on mothers who gave birth in the period 2 November, 2001, to 1 March, 2002, and their children. The administrative data includes the exact date of birth and allows a child to be linked with the mother and the father. The data also provides a few characteristics of the newborn child (gender, birthweight, and gestation length). Detailed socioeconomic information is available on both mothers and fathers, including age, education, earnings among others. ${ }^{11}$

For each type of maternity leave payment received by either the mother directly or by the employer as compensation, ${ }^{12}$ we know the date of the first pay-

\footnotetext{
${ }^{11}$ For a full list of included control variables see Table 5.

${ }^{12}$ If employers pay their workers full-wage compensation during parental leave, the employer
} 
ment and the total benefit transfer. We are thereby able to compute the length of maternity leave based on the observed benefit payments and the relevant benefit rates. Figure 2 shows the average leave taken by mothers before and after the reform. ${ }^{13}$ We define maternity leave to be leave taken within two years of the child's birth (or until the birth of a new child if this occurs within two years of the first child's birth).

To construct health outcomes for the mother and child, we use data on hospital admissions maintained by the National Board of Health in Denmark. This includes information on emergency department visits, outpatient visits, and hospital admissions in both regular hospitals and psychiatric hospitals. For each admission, we have information on the admission date, length of stay, and the relevant diagnosis. With exact admission dates it is possible to construct measures of the number of admissions within a specific period of time after childbirth. Hence, we are able to construct measures counting the number of admissions within exactly one year, two years etc. after childbirth for both mother and child. Using the exact dates allows us to define the outcome measures such that they are measured in the exact same way for the treatment and control groups. Finally, we use data on prescription drug purchases to construct a measure of whether or not the mother has received antidepressants, for example, in relation to a post-partum depression. This measure may be able to capture minor health changes that do not necessarily result in a hospital admission. ${ }^{14}$

To be specific, we construct the following health outcomes for the mothers: The number of hospital admissions (inpatient), the number of non-birth hospital admissions (i.e. inpatient admissions unrelated to any later childbirths), being

gets a refund from the state corresponding to the payment that the state would otherwise have paid in leave benefits.

${ }^{13}$ Prior to the reform parents were entitled to what was known as 'Børnepasningsorlov' (childcare leave) at a reduced benefit level. According to the rules of this leave scheme, it was supposed to be used before the child turned nine years old implying that this was not necessarily maternity leave per se. However, in practise many women used this leave scheme to extend their maternity leave. Therefore, we include this type of leave in the computation of maternity leave if it was used within the first two years after birth.

${ }^{14}$ It would also be of interest to look at the number of doctor visits, see e.g. Currie and Gruber (1996), but we do not have access to this information. 
hospitalized with depression ${ }^{15}$ and receiving antidepressants ${ }^{16}$. Correspondingly, we construct the following health outcomes for children: The number of hospital admissions(inpatient) and the number of emergency department visits. Since we know the exact dates of both admissions and prescription drug purchases, we can define the timing of the outcomes very precisely. We focus on outcomes one and three years after childbirth. For example, the number of hospital admissions within one year after childbirth for a mother who has given birth on 15 January, 2002 is measured from 16 January, 2002, to 15 January, 2003. For being hospitalized with a depression, we also allow for the hospitalization to have occurred within the last half of the pregnancy.

Finally, we also consider family well-being in a broader sense. We consider the effect of the length of maternity leave on the probability of getting a new child or experiencing a relationship dissolution. With register data on all births, it is easy to measure if the mother has a new child within the period of interest. We define a relationship dissolution to have occurred if the woman is not married to or cohabiting with the same person as when the child was born. ${ }^{17}$

\subsection{Sample Selection}

Table 4 provides an overview of the sample selection process. First, we select all births occurring from 60 days before 1 January until 60 days after 1 January. This sample consists of 20,905 births. We disregard all births where there are multiple fathers or multiple mothers registered. We match the sample of births where the mother and father can be uniquely identified with data from the register containing information on parental leave. We drop those observations, where we cannot find any parental leave record for the mothers. This happens to a relatively large extent since some mothers are not eligible for maternity leave

\footnotetext{
${ }^{15}$ We define a mother as being hospitalized with depression if she has been admitted to a psychiatric hospital with one of the following ICD-10 diagnosis codes: F30-F34, F38-F45, F48, or F50.

${ }^{16}$ Antidepressants are prescription drugs with ATC code MN06A.

${ }^{17}$ Opposed to all the other outcomes, we do not have the exact date of a relationship dissolution. In the registers, civil status is registered on 1 January each year.
} 
benefits at the level of unemployment insurance. ${ }^{18}$ For example, this is the case if the mother is enrolled in an education or on social assistance. In these cases different benefit programs exist to help the mother. However, this makes the calculation of total leave days from total benefit payments rather complicated. Therefore, we delete births where this is the case. Thus, the sample consists of mothers who are employed or unemployed with unemployment insurance. The final sample contains 15,494 births (of 15,449 mothers). Out of this sample 8,149 are in the treatment group (born after 1 January), while 7,345 are in the control group (born before 1 January). The difference in the size of the treatment and control groups is not caused by sample selection as can be seen from Table 4, since the difference is also present comparing the number of births in the control group and in the treatment group. This gives rise to some concern since the pattern is consistent with parents anticipating the reform and postponing childbirth until after implementation of the reform. However, this is highly unlikely given the timing of the legislative procedure since the reform was first passed in March 2002. Figure 3 shows the number of births per month from 2000 to 2003. A similar pattern of births is seen in all years, suggesting that the pattern is not driven by the reform.

\subsection{Descriptive Statistics}

In Table 5, we report descriptive statistics for the treatment and control groups for the control variables. In the treatment effect literature, it is common practice to compare the means of the control and treatment groups in order to check for balance in background characteristics. However, in the context of a regression discontinuity design, a more informative test estimates the actual jump in each covariate on 1 January. Table 5 reports both of these tests. For almost all of the control variables there is no difference between the treatment group and control group using either test. Overall, we interpret the results of the tests as supporting

\footnotetext{
${ }^{18}$ Ideally we would know which mothers were eligible for maternity leave, but the register data does not provide this information directly. However, mothers are actually obligated to take the first two weeks of maternal leave after childbirth. We thereby argue that we are able to identify all eligible mothers using the maternity leave payment records as described above.
} 
our identifying assumption that childbirths within the window of 60 days before and after 1 January are comparable and only differ by the mother's access to leave schemes.

In Table 6, we show descriptive statistics for the length of maternity leave, the length of paternity leave, and all outcome variables. There appear to be several significant differences in means across the treatment and control groups. However, testing if the jump on 1 January is significant reveals that many of these differences disappear controlling for distance. This is the first indication of small or no effects of the increase in maternity leave.

\section{$5 \quad$ Results}

In this section we present our estimates of the effect of maternity leave on mother and child health and family well-being. First, we present the IV results of the effect of maternity leave on child health, i.e. the number of hospital admissions and the number of emergency department visits. For the mother, we consider four different outcomes: The number of hospital admissions, the number of nonbirth hospital admissions, being hospitalized with a depression, and receiving antidepressants. Subsequently, we present evidence on two indicators of family well-being: Getting a new child and experiencing a relationship dissolution. We present estimation results for outcomes measured within one and three years after childbirth. ${ }^{19}$

We then proceed by presenting graphical evidence of the significant effects obtained in the IV regressions. The purpose of this is to show that the results are not driven by some arbitrary functional form assumptions in the estimation. Finally, we investigate if there are differential treatment effects by whether or not the child is the firstborn, maternal income, and length of maternal education.

\footnotetext{
${ }^{19}$ We have estimated the effects on all outcomes measured within one to five years after childbirth. These results show the same pattern as those presented and are available upon request.
} 


\subsection{Estimation Results}

Table 7 shows the estimation results for the child and maternal health outcomes. $^{20}$ The reported estimates are IV estimates using $T_{i}$, an indicator that equals one if the mother gave birth after 1 January, 2002, as an instrument for the length of maternity leave. For ex positional purposes, the length of maternity leave is divided by 100 days, and the estimates thus reflect the effect of increasing the length of maternity leave by 100 days. In order to get the full effect of the reform, one should multiply the estimates by the average difference in maternity leave (32 days) divided by 100. Column (1) reports the results without control variables, but where the function of the forcing variable $\left(f\left(d_{i}\right)\right.$ in equation $\left.(2)\right)$ is linear and the slope is allowed to differ on each side of the discontinuity. ${ }^{21}$

Column (2) includes characteristics of the parents. Since Table 5 reported almost the same means of the control variables for the treatment and control groups and insignificant jumps, we would not expect to see a large difference in the estimated coefficients when we include control variables in the specification. In fact, none of the estimates change significantly. In column (3), we additionally control for the characteristics of the newborn and the length of paternity leave. This yields similar results. As mentioned previously, the average length of paternity leave only increases from 15.8 to 16.1 days following the reform. And, the estimated jump in the length of paternity leave is even negative, albeit small, cf. Table 5. This is of course an endogenous variable, so any regression controlling for it should be interpreted with caution. However, if the effect on the outcomes was driven by this small change in the length of paternity leave, we would expect the estimates to change substantially when the variable is included. Since the changes in the estimates are very small, we find it safe to assume that the reported estimates reflect changes in the length of maternity leave. Our preferred

\footnotetext{
${ }^{20}$ Due to spacial considerations, we do not report the first-stage regression estimates. These are available upon request. For the preferred model specification, the F-statistic of the firststage regression for the maternal (child) outcomes is $30.4(31.1)$ and the t-statistic of the instrument is $9.7(9.9)$.

${ }^{21}$ We have investigated the robustness of the estimates by allowing for a more flexible form specification of the assignment variable. We have included up to third degree polynomials. We find no qualitative differences. The results are available upon request.
} 
specification is the one in column (4), where we include characteristics of both the parents and child but do not include the length of paternity leave. Again, the estimates do not change much.

Looking at the outcomes for the child within one year after birth, we find no significant effect on the number of hospital admissions. However, a hospital admission is also an indicator of rather severe health problems, so this may not be that surprising. Therefore, we also consider a less extreme child health outcome; the number of emergency visits. This is often a good predictor of future child achievement in e.g. the education system, see e.g. Currie, Stabile, Manivong, and Roos (2010). The point estimate is positive but highly insignificant. Turning to the same outcomes within three years after birth, we again find no significant effects. We thus find no indication that the expansion in maternity leave affects children's short-term health outcomes.

For the maternal outcomes, we first turn to the effect of maternity leave on the number of hospital admissions. We find that the number of hospital admissions is negatively affected by an increase in the length of maternity leave. Mothers with longer maternity leave spells have fewer hospital admissions. In fact, increasing maternity leave by 100 days leads to a decrease in the number of hospital admissions within one year after childbirth of about -0.11 . This is a relatively large effect given that the average number of hospital admissions is only about 0.16 for the control group. The estimated effect even persists and is a little bit higher for the number of hospital admissions within three years after childbirth. To some extent, it appears that the estimated effect is driven by differences in the propensity to have a new child, since the estimated effect becomes smaller and less significant if we consider the number of non-birth hospital admissions. The estimated effect on the number of non-birth hospital admissions within one year after childbirth is still negative and marginally significant though. Finally, we consider the effect of increasing the length of maternity leave on being hospitalized with a depression and receiving antidepressants. We find no significant effects of increasing the length of maternity leave in any of the specifications. ${ }^{22}$

\footnotetext{
${ }^{22}$ In addition, we have performed the estimations for the number of hospitalizations with a
} 
In Table 8, we present the estimated effects on family well-being, i.e. having a new child and experiencing relationship dissolution. We find that increasing the length of maternity leave by 100 days decreases the probability of having a new child within three years after childbirth by about 6 percentage points. Thus, extending maternity leave appears to have a negative effect on fertility — at least in the short run. One potential explanation for this could be that women prefer to return to the labor market for some minimum amount of time before re-exiting to maternity leave. It may not be optimal to have very short work spells. However, in our preferred specification the standard error is 0.044 and thus the estimate is insignificant. We find small and insignificant effects on relationship dissolution.

Finally, Figures 4 (child health), 5 (maternal health), and 6 (family wellbeing) show the IV estimates for all main outcomes measured within one to five years after childbirth. This gives a graphical illustration of possible time persistence or variation in the estimated effects. The graphs confirm that there seems to be at most very limited effects of increasing the length of maternity leave on maternal and child health and family well-being.

\subsection{Graphical Results}

One of the advantages of using a regression discontinuity design is that the identification strategy makes it easy to make sure that results are not driven by functional form assumptions. We thus present a graphical analysis of the discontinuity in the outcomes that turned out to be associated with significant effects: The number of hospital admissions and the number of non-birth hospital admissions (for the mother). Figures 7 and 8 show the average number of hospital admissions within one and three years after childbirth including and excluding birth-related hospital admissions, respectively. For both outcomes, it is relatively clear from the graphs that there is a shift in the levels around 1 January, 2002.

depression and the amount (in milligrams) of antidepressants received. We find no effect on these outcomes. The results are available upon request. 


\subsection{Sensitivity and Window Size}

The sample used in the above analysis was based on childbirths within a window of 60 days around 1 January, 2002. To investigate the sensitivity of the results to the choice of window, we estimate the preferred model, specification (4) in Tables 7 and 8 , for samples based on childbirths within a window of $30,50,60,90,120$, and 150 days around 1 January, 2002. For each resulting sample, we also perform a joint test for discontinuities in the covariates, see Lee and Lemieux (2010), to check for balancing of the covariates. ${ }^{23}$

Figures 9 and 10 show the estimated effects of increasing maternity leave on the number of hospital admissions for the child and mother, respectively, using different window sizes. As expected, the confidence bands narrow when the sample size increases. However, the magnitude of the estimates is generally unchanged for the mother. For the child, the size of the estimates appears to be more sensitive to the choice of window. However, the test for jumps in the covariates suggests that estimations using the larger window sizes are likely to suffer from misspecification. This highlights the potential problem of using a window of six years as in e.g. Baker and Milligan (2008b). Overall, the results suggest that the window of 60 days is reasonable, and that the results are not particularly sensitive to this choice. One potential explanation for why we cannot defend using very large window sizes is that there is some seasonal variation in child and parental socio-economic and health characteristics, as suggested by Bound and Jaeger (1996) and Buckles and Hungerman (2013), which our current choice of functional form does not take into account.

\subsection{Heterogeneous Treatment Effects}

Based on the results presented so far, it does not seem as if an increase in the length of maternity leave has much effect on family health and well-being. However, it is possible that changes in the length of maternity leave have differential

\footnotetext{
${ }^{23}$ If the null of no discontinuity in covariates is rejected, it indicates misspecification or an invalid regression discontinuity design. The resulting $\chi^{2}$-test statistics and p-values (in brackets) are as follows: 42.9 [0.115] for 30 days, 31.8 [0.526] for 50 days, 35.1 [0.369] for 60 days, 43.1 [0.112] for 90 days, $51.5[0.021]$ for 120 days, and 51.9 [0.019] for 150 days.
} 
effects on subgroups of individuals. Therefore, we extend the analysis to allow for heterogeneous responses by observable characteristics. Specifically, we investigate whether there are differential effects on maternal and child health by whether or not the child is the firstborn, maternal income, and length of maternal education. Generally, we find little evidence of any substantial effects although we do see some differences across subgroups. ${ }^{24}$

We incorporate the possibility of heterogeneous effects by interacting the variable measuring the length of maternity leave with group-specific indicators. These terms are then instrumented with interactions of the indicator for childbirth after 1 January, 2002, and the group-specific indicators. We also allow for different slopes across subgroups by interacting the terms involving the forcing variable, $d_{i}$, with the group-specific indicators. The estimated effects are presented in Table 9. Model (1) simply replicates the main treatment effects of section 5.1 whereas models (2), (3), and (4) allow the effects of an increase in the length of maternity leave to differ across birth order (firstborn versus higher-order), maternal income, and length of maternal education, respectively. The columns with the main effects present the estimated effects for the baseline subgroup. The other columns contain the interaction effects. For example, for firstborn children, the effect of increasing the length of maternity leave by 100 days on the number of hospital admissions within one year after birth is $-0.011-0.015=-0.026$. And, we can see from the table that we cannot reject that the effect is the same for firstborn and higher-order born children. Overall, we find no evidence suggesting heterogeneous effects on child health. The results are more mixed when we consider maternal health.

We find that the estimated effects are generally higher for first-time mothers. The interpretation of this is that first-time mothers benefit to a lesser extent from an increase in the length of maternity leave. Specifically, looking at the number of hospital admissions, the effect of increasing the length of maternity leave is higher for first-time mothers. Within one year after childbirth, the num-

\footnotetext{
${ }^{24}$ We have also investigated labor market status, marital status, and gender of the child which yielded the same overall conclusion. The results are available upon request.
} 
ber of hospital admissions decrease by 0.118 per 100 days of extra leave for those who are not first-time mothers. However, for first-time mothers the number of hospital admissions decrease only by $0.097(-(-0.118+0.021))$. This difference persists after three years and if we only consider the number of non-birth hospital admissions, albeit with a higher significance level. We see the same pattern for being hospitalized with a depression.

While we cannot give a precise answer, we can hypothesize about the reasons why first-time mothers would be less affected by an increase in the length of maternity leave. First of all, mothers who already have one or more children are potentially under more stress since they have a larger family. A mother with only one child may be able to find more leisure time or time for work which may reduce the stress she faces. On the other hand, one could also speculate that e.g. since second-time mothers are more experienced they would be better able to cope with any potential problems in the household or at work. It is also possible that first-time mothers have different needs than e.g. second-time mothers to return to work and their adult networks.

When we look at whether the effects differ by the level of maternal income, we find mixed effects. The effect of increasing maternity leave on the number of hospital admissions is generally lower for low-income mothers. ${ }^{25}$ That is, they benefit more in terms of less admissions as a result of the reform compared to other mothers. This is the case regardless of whether we consider all hospital admissions or only non-birth hospital admissions and the pattern is the same within one and three years after childbirth. However, when we consider being hospitalized with a depression and receiving antidepressants, we find that the effects are higher for low-income mothers although they are typically insignificant making it hard to draw any general conclusions.

Finally, we consider potential differential responses by length of maternal education. The baseline category consists of mothers who have more than 13

\footnotetext{
${ }^{25}$ Mothers are classified as having low income, if they are in the lowest income quartile in the sample. Of course, this does not correspond to the lowest quartile in society as a whole since our sample consists of those who are either employed or unemployed with unemployment insurance.
} 
years of education. For this group, we generally see that increasing the length of maternity leave has negative but highly insignificant effects on the number of hospital admissions. For mothers with no more than 10 years of education, the estimated effects are substantially lower, but for the number of hospital admissions, we cannot reject that the effects are the same as for the baseline category with more years of education. However, there is some indication that mothers with less than 10 years of education benefit more from increasing the length of maternity leave in terms of the probability of being hospitalized with a depression and receiving antidepressants. For example, for mothers with more than 13 years of education, increasing the length of maternity leave by 100 days increases the probability of receiving antidepressants by 4.5 percentage points. In comparison, for mothers with less than 10 years of education, the corresponding number is -15.2 percentage points.

Overall, the analysis suggests limited effects of the length of maternity leave on child and maternal health outcomes. For maternal health outcomes, we do find some indication that different mothers respond differently to the expansion in maternity leave. The results point in the direction that any beneficial effects of increasing the length of maternity leave are higher for mothers or families that have less resources where a low-resource family is interpreted broadly as e.g. a family with many children, low income, or low education level.

\section{Conclusion}

We use a reform of the maternity leave scheme in Denmark that was implemented on January 1, 2002, to identify the effect of increasing the length of maternity leave on a range of child and maternal health outcomes and family well-being. The implementation of the reform generates a regression discontinuity setting, where mothers of children born before 1 January, 2002, faced different rules than mothers of children born after 1 January, 2002. The reform implied an increase in the average length of maternity leave of about 32 days.

We use this setup to study the effect of maternity leave on a wide range 
of health-related outcomes including the number of hospital admissions (of both mother and child), the number of emergency department visits (child), being hospitalized with a depression (mother), receiving anti-depressants (mother), getting a new child, and experiencing a relationship dissolution. We find some indication of a positive effect of increasing the length of maternity leave on the number of hospital admissions for the mother, but overall the health and well-being of families appear to be largely unaffected.

Allowing for heterogeneous effects by birth order, maternal income, and the length of maternal education, we find no evidence suggesting that an increase in maternity leave affects child health. However, for maternal health outcomes, our analysis does suggest differential responses to the expansion in maternity leave across subgroups. Any beneficial effects of increasing the length of maternity leave appear to be higher for low-resource families in the sense that the beneficial effects are higher for mothers with more children, lower income, and less years of education. Overall, our results are consistent with those of many earlier studies that find no or limited effects of expanding maternity leave schemes-especially in the long run. We show that even for health outcomes measured in the relatively short run, there does appear to be limited effects.

\section{References}

Angrist, J. D., And G. W. Imbens (1995): "Two-Stage Least Squares Estimation of Average Causal Effects in Models with Variable Treatment Intensity," Journal of the American Statistical Association, 90(430), pp. 431-442.

Angrist, J. D., And V. Lavy (1999): "Using Maimonides' Rule to Estimate the Effect of Class Size on Scholastic Achievement," The Quarterly Journal of Economics, 114(2), 533-575.

Baker, M., And K. Milligan (2008a): "Evidence from Maternity Leave Expansions of the Impact of Maternal Care on Early Child Development," NBER Working Paper Series, 13826. 
(2008b): "Maternal Employment, Breastfeeding, and Health: Evidence from Maternity Leave Mandates," Journal of Health Economics, 27(4), 871887.

Björklund, A., and K. G. Salvanes (2011): "Chapter 3 - Education and Family Background: Mechanisms and Policies," vol. 3 of Handbook of the Economics of Education, pp. 201 - 247. Elsevier.

Bound, J., And D. A. Jaeger (1996): "On the Validity of Season of Birth as an Instrument in Wage Equations: A Comment on Angrist and Krueger's 'Does Compulsory School Attendance Affect Schooling and Earnings?," NBER Working Paper Series, 5835.

Buckles, K. S., and D. M. Hungerman (2013): "Season of Birth and Later Outcomes: Old Questions, New Answers," The Review of Economics and Statistics, 95(3), 711-724.

Currie, J., And J. Gruber (1996): "Health Insurance Eligibility, Utilization of Medical Care, and Child Health," The Quarterly Journal of Economics, 111(2), $431-66$.

Currie, J., M. Stabile, P. Manivong, and L. L. Roos (2010): "Child Health and Young Adult Outcomes," Journal of Human Resources, 45(3), 517-548.

Dahl, G. B., K. V. Løken, M. Mogstad, and K. V. Salvanes (2013): "What Is the Case for Paid Maternity Leave?," Working Paper 19595, National Bureau of Economic Research.

Dustmann, C., And U. Schönberg (2012): "Expansions in Maternity Leave Coverage and Children's Long-Term Outcomes," American Economic Journal: Applied Economics, 4(3), 190-224.

Humlum, M. K., and R. M. VeJlin (2013): "THE RESPONSES OF YOUTH TO A CASH TRANSFER CONDITIONAL ON SCHOOLING: A QUASIEXPERIMENTAL STUDY," Journal of Applied Econometrics, 28(4), 628649. 
Lalive, R., and J. Zweimüller (2009): "How Does Parental Leave Affect Fertility and Return to Work? Evidence from Two Natural Experiments," The Quarterly Journal of Economics, 124(3), 1363-1402.

Lee, D. S., And T. Lemieux (2010): "Regression Discontinuity Designs in Economics," Journal of Economic Literature, 48(2), 281-355.

Liu, Q., And O. N. Skans (2010): "The Duration of Paid Parental Leave and Children's Scholastic Performance," The BE Journal of Economic Analysis \&6 Policy, 10(3).

Nielsen, H. S. (2009): "Causes and Consequences of a Father's Child Leave: Evidence from a Reform of Leave Schemes," IZA Discussion Papers 4267, Institute for the Study of Labor (IZA).

Rasmussen, A. W. (2010): 'Increasing the length of parents' birth-related leave: The effect on children's long-term educational outcomes," Labour Economics, 17(1), 91-100.

Rossin, M. (2011): "The effects of maternity leave on children's birth and infant health outcomes in the United States," Journal of Health Economics, 30(2), $221-239$.

Sundhedsstyrelsen (2008): Amning - En håndbog for sundhedspersonale. Sundhedsstyrelsen (National Board of Health, Denmark). 


\section{A Figures}

Figure 1: The length of maternity leave by date of childbirth

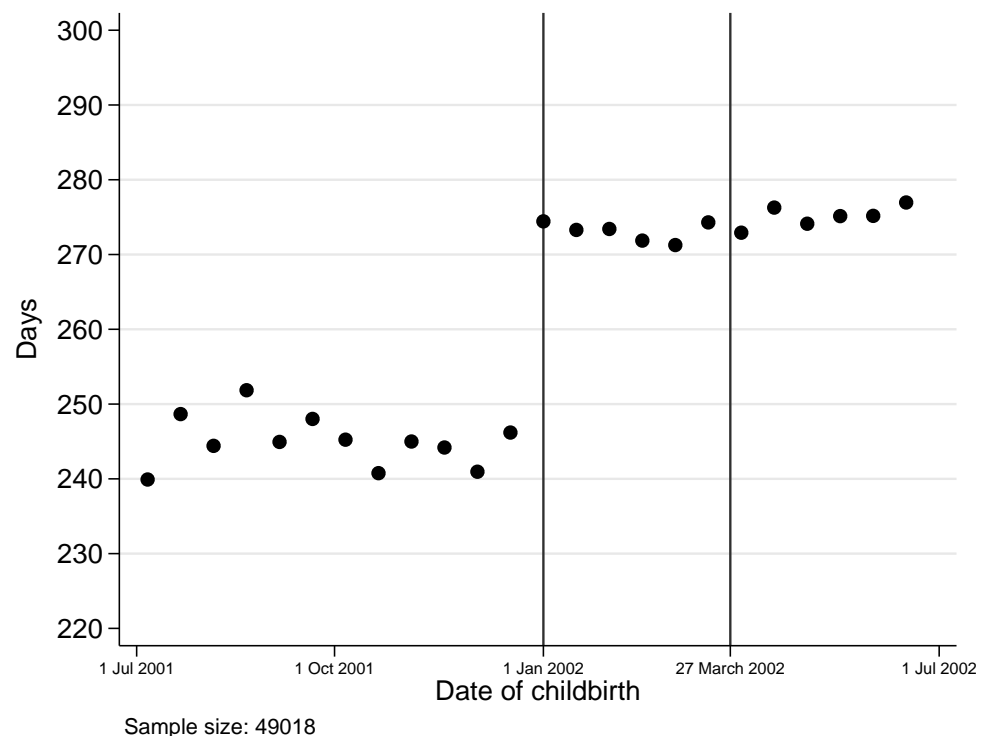

Figure 2: The length of maternity leave by distance from 1 January, 2002, to date of childbirth

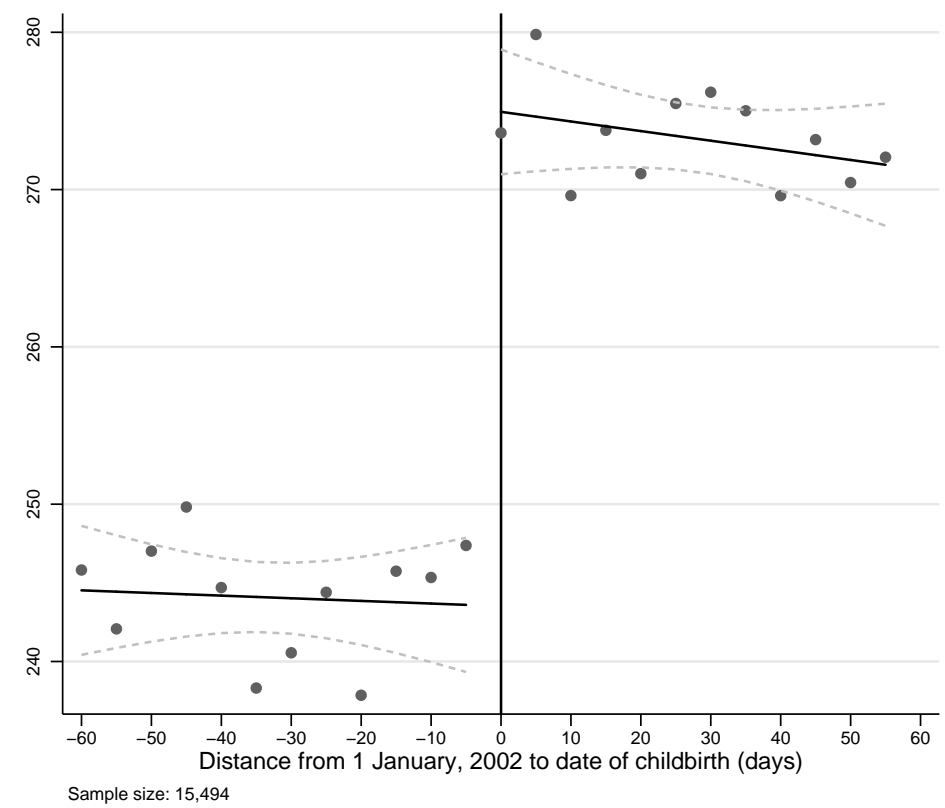


Figure 3: Number of births by month and year

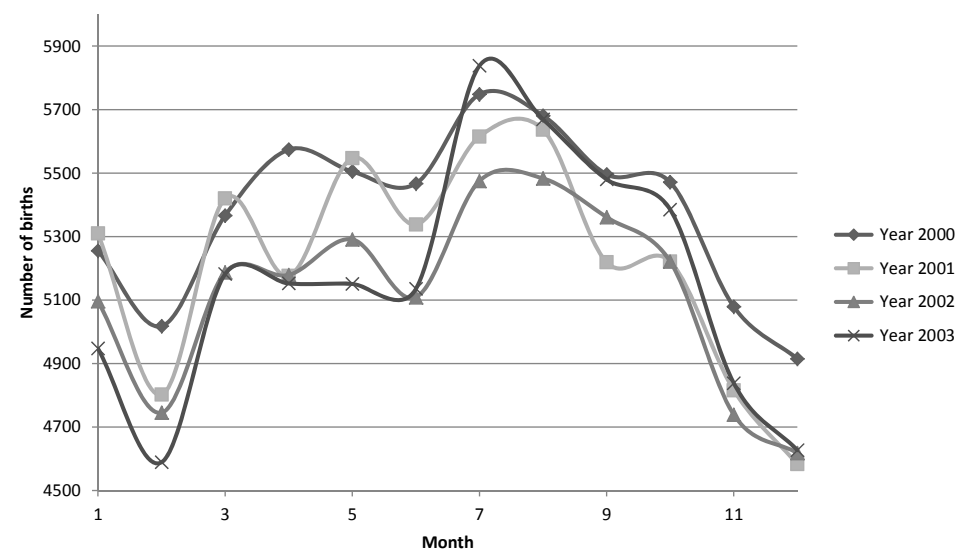


Figure 4: IV estimates on child outcomes measured within one to five years after birth

(a) Number of hospital admissions

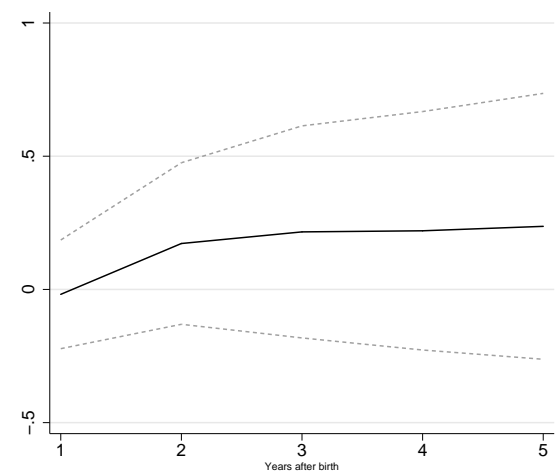

(b) Number of emergency department visits

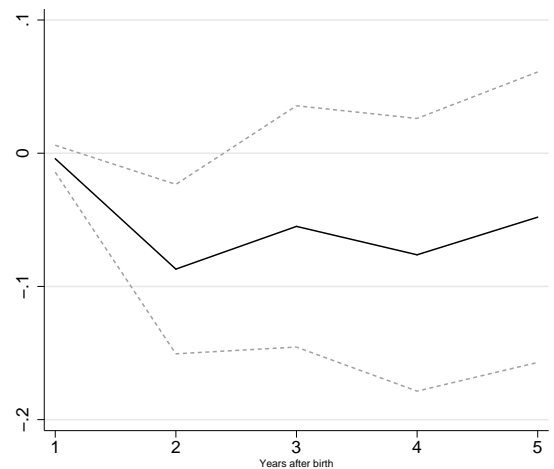

Figure 5: IV estimates on maternal outcomes measured within one to five years after childbirth

(a) Number of hospital admissions

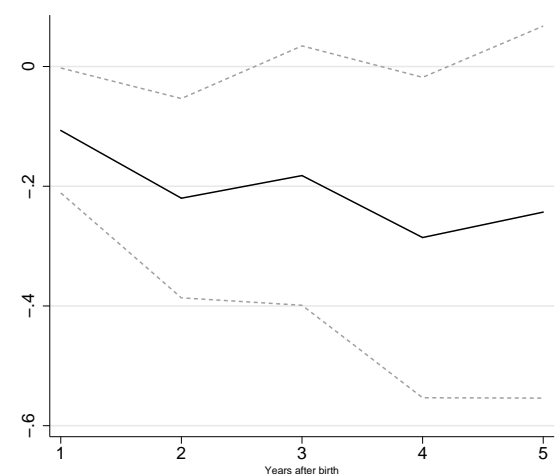

(c) Hospitalized with a depression

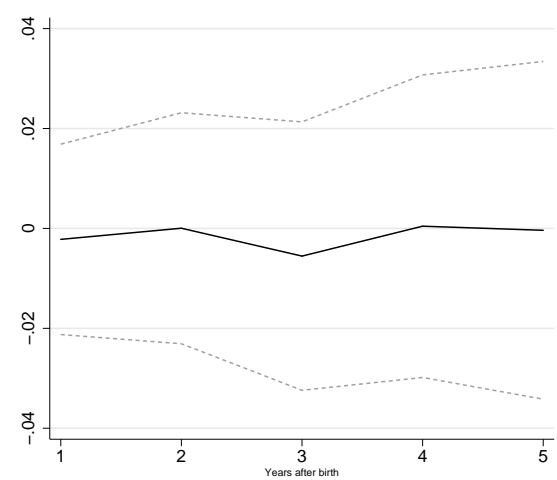

(b) Number of non-birth hospital admissions

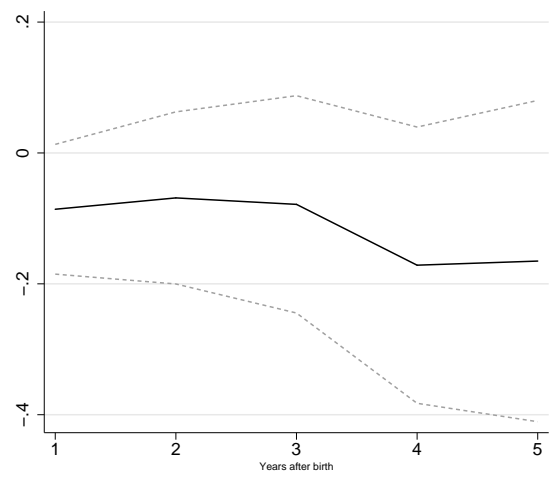

(d) Receiving antidepressants

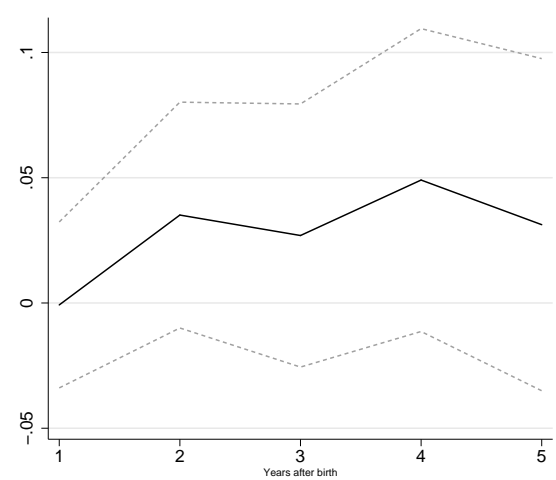


Figure 6: IV estimates on family outcomes measured within one to five years after birth

(a) Experiencing relationship dissolution

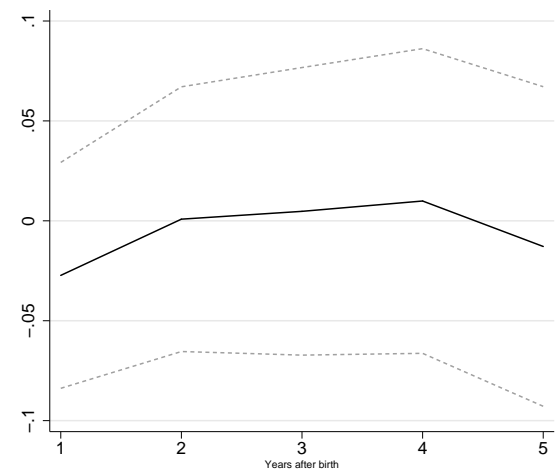

(b) Having a new child

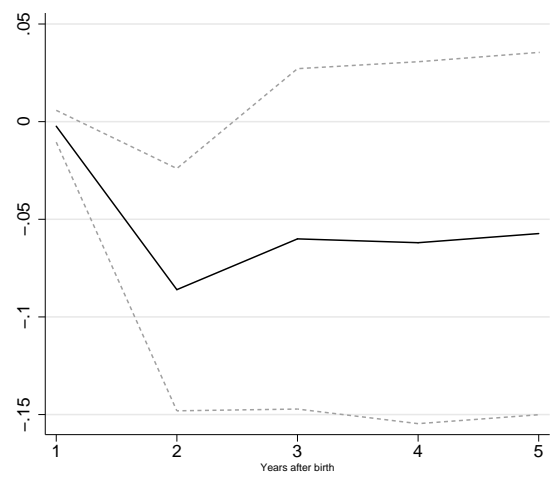


Figure 7: Number of hospital admissions (mother) by distance to 1 January, 2002. Scatter plots are overlaid with fitted values and 95 percent confidence bands from a linear regression. Days are grouped in 5-day bins.

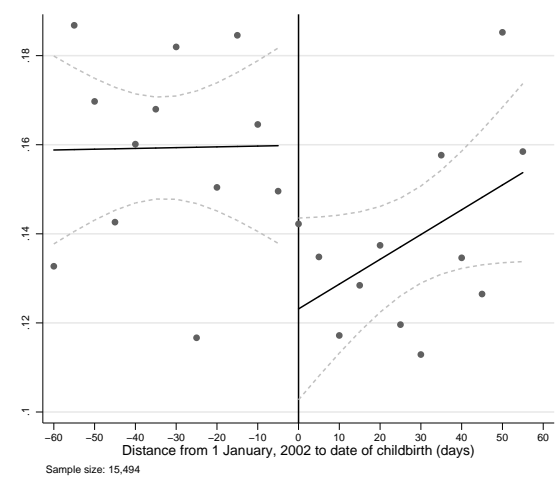

(a) Within one year after childbirth

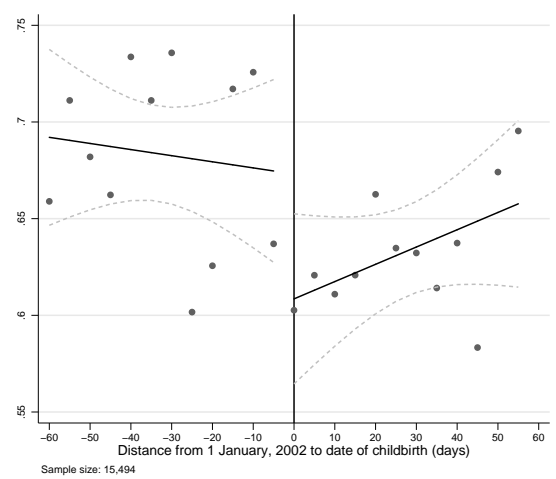

(b) Within three years after childbirth

Figure 8: Number of non-birth hospital admissions (mother) by distance to 1 January, 2002. Scatter plots are overlaid with fitted values and 95 percent confidence bands from a linear regression. Days are grouped in 5-day bins.

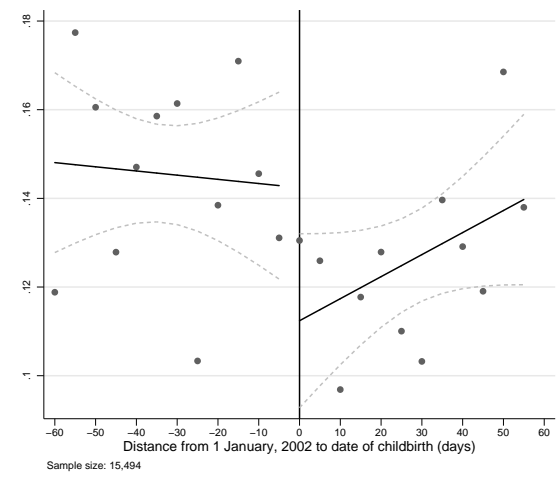

(a) Within one year after childbirth

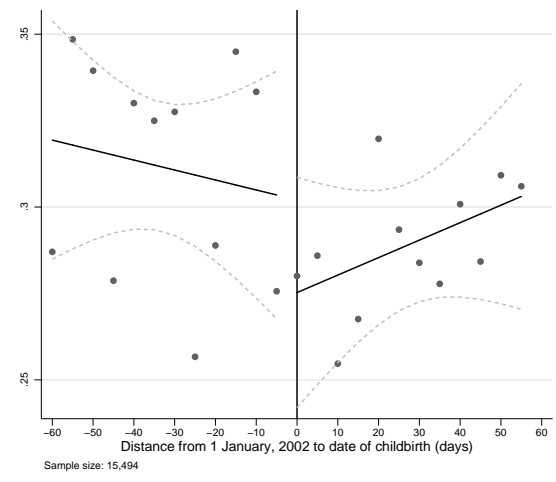

(b) Within three years after childbirth 
Figure 9: IV estimates of the effect of increasing maternity leave on the number of hospital admissions for the child for different window sizes.

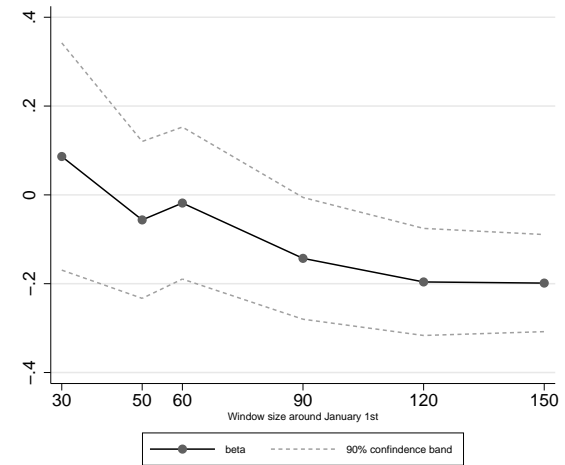

(a) Within one year after childbirth

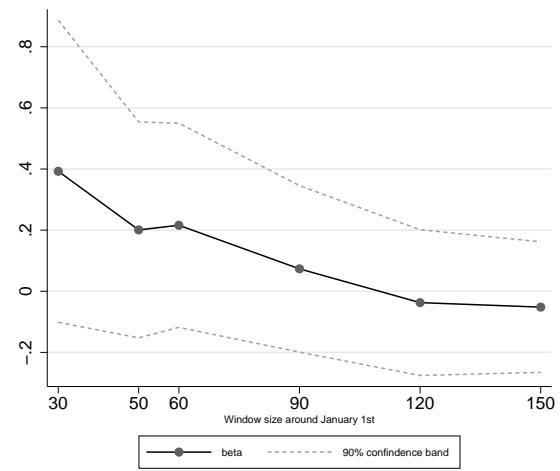

(b) Within three years after childbirth

Figure 10: IV estimates of the effect of increasing maternity leave on the number of hospital admissions for the mother for different window sizes.

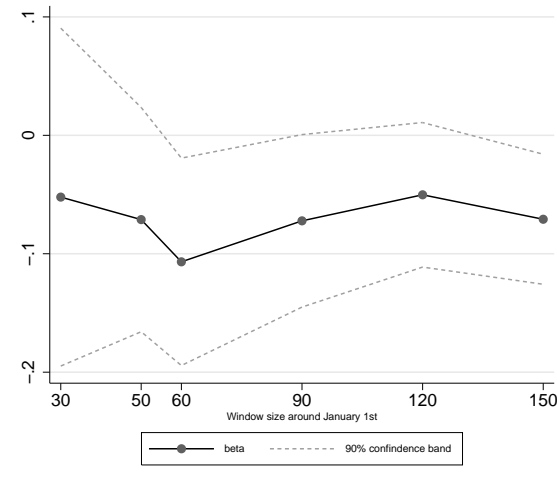

(a) Within one year after childbirth

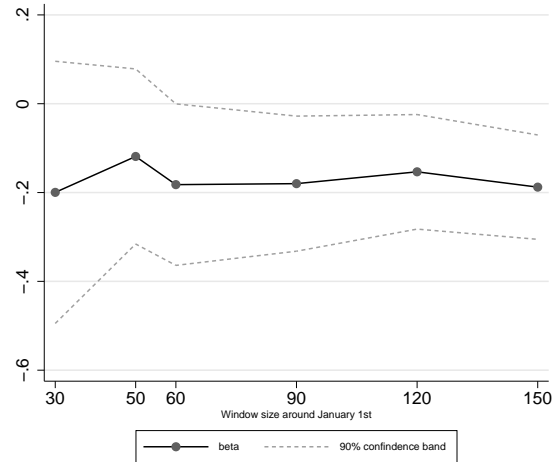

(b) Within three years after childbirth 


\section{B Tables}

Table 1: Overview of Benefit Rules

\begin{tabular}{lcc}
\hline \hline Maternity leave & \multicolumn{2}{c}{ Weeks of benefits } \\
\hline Pre-birth & 4 \\
Post-birth & 14 \\
& Pre-reform & Post-reform \\
& 10 & $32^{a}$ \\
At reduced benefit level (60 percent) & 52 & \\
\hline \hline
\end{tabular}

a) Options include sharing with the father, extending the benefit period in exchange for a lower benefit level, and postponing part of the leave

Table 2: Implementation of Reform

\begin{tabular}{lc}
\hline \hline Date of giving birth & Rule set \\
\hline Prior to 1 January, 2002 & pre-reform rules apply \\
1 January, 2002 - 26 March, 2002 & optional \\
After 26 March, 2002 & post-reform rules apply \\
\hline \hline
\end{tabular}


Table 3: Characterization of Mothers' Leave Spells Pre- and Post-Reform

\begin{tabular}{|c|c|c|c|c|c|c|c|}
\hline $\begin{array}{l}\text { Mothers giving birth } \\
\text { prior to } 1 \text { January, } 2002\end{array}$ & $\begin{array}{l}\text { Max. } \\
\text { weeks } \\
\text { (cum.) }\end{array}$ & Percent & $\begin{array}{c}\text { Percent } \\
\text { (cum.) }\end{array}$ & $\begin{array}{l}\text { Mothers giving birth } \\
\text { after } 1 \text { January, } 2002\end{array}$ & $\begin{array}{l}\text { Max. } \\
\text { weeks } \\
\text { (cum.) }\end{array}$ & Percent & $\begin{array}{c}\text { Percent } \\
\text { (cum.) }\end{array}$ \\
\hline $\begin{array}{l}\text { Post-birth } \\
\text { Maternity leave, } 14 \text { weeks } \\
\text { Parental leave, } 10 \text { weeks }\end{array}$ & $\begin{array}{l}14 \\
24\end{array}$ & $\begin{array}{c}5.1 \\
89.0\end{array}$ & $\begin{array}{c}5.1 \\
94.1\end{array}$ & $\begin{array}{l}\text { Post-birth } \\
\text { Maternity leave, } 14 \text { weeks } \\
\text { Parental leave, } 32 \text { weeks } \\
\text { Parental leave, extending } 32 \text { weeks } \\
\text { with } 14 \text { weeks (at reduced benefit } \\
\text { level) }\end{array}$ & $\begin{array}{l}14 \\
46 \\
60\end{array}$ & $\begin{array}{c}3.3 \\
94.0 \\
2.6\end{array}$ & $\begin{array}{c}3.3 \\
97.3 \\
99.9\end{array}$ \\
\hline \multicolumn{4}{|c|}{ childcare leave (additional leave at reduced benefit level) } & \multirow{6}{*}{\multicolumn{3}{|c|}{$\begin{array}{l}\text { childcare leave (postponing part of the } 32 \text { weeks) } \\
0 \text { weeks } \\
8 \text { to } 13 \text { weeks } \\
1 \text { to } 32 \text { weeks (need employer's ac- } \\
\text { ceptance) }\end{array}$}} & \\
\hline 0 weeks & 24 & 44.9 & 44.9 & & & & \\
\hline 8 to 13 weeks & 37 & 21.1 & 66.0 & & & & \\
\hline $\begin{array}{l}8 \text { to } 26 \text { weeks (if starting before } \\
\text { child turns } 1 \text { year old) } \\
8 \text { to } 52 \text { weeks (need employer's ac- } \\
\text { ceptance) }\end{array}$ & 50 & 20.1 & 86.1 & & & & \\
\hline - up to 36 weeks & 60 & 5.8 & 91.9 & & & & \\
\hline - up to 52 weeks & 76 & 7.0 & 99.0 & & & & \\
\hline
\end{tabular}

Table 4: Sample Selection

\begin{tabular}{l|rrrrrr}
\hline \hline & \multicolumn{2}{|c}{ All } & \multicolumn{2}{c}{ Before 1 January } & \multicolumn{2}{c}{ After 1 January } \\
& $\begin{array}{c}\text { Number } \\
\text { of births }\end{array}$ & Percent & $\begin{array}{c}\text { Number } \\
\text { of births }\end{array}$ & Percent & $\begin{array}{r}\text { Number } \\
\text { of births }\end{array}$ & Percent \\
Description of sample selection & 20,905 & 100.0 & 10,088 & 100.0 & 10,817 & 100.0 \\
\hline Born 2 November, 2001 - 1 March, 2002 & 20,874 & 99.9 & 10,066 & 99.8 & 10,808 & 99.9 \\
$\begin{array}{l}\text { Excluding births registered to multiple } \\
\text { mothers or fathers }\end{array}$ & 15,494 & 74.1 & 7,345 & 72.8 & 8,149 & 75.3 \\
Mother eligible for leave benefits & & & & &
\end{tabular}


Table 5: Descriptive Statistics for Control Variables

\begin{tabular}{|c|c|c|c|c|c|c|c|}
\hline \multirow[t]{2}{*}{ Date of childbirth } & \multicolumn{2}{|c|}{ Before 1 January } & \multicolumn{2}{|c|}{ After 1 January } & \multirow{2}{*}{$\begin{array}{l}\text { Test: } \\
\text { Equal means } \\
\text { Difference } \\
\end{array}$} & \multicolumn{2}{|c|}{$\begin{array}{l}\text { Test: } \\
\text { Jump at the cutoff } \\
\text { date equal to zero }\end{array}$} \\
\hline & Mean & Std.dev & Mean & Std.dev & & Jump & Std.err. \\
\hline Child characteristics & & & & & & & \\
\hline Boy & 0.499 & & 0.506 & & 0.007 & 0.015 & $(0.016)$ \\
\hline Birthweight (grams) & 3,471 & $(734)$ & 3,506 & $(672)$ & $35^{* * *}$ & 22 & $(23)$ \\
\hline Gestation (days) & 276.369 & $(29.921)$ & 276.842 & $(27.853)$ & 0.474 & 0.027 & $(0.945)$ \\
\hline Twin or triplet & 0.0319 & & 0.025 & $(0.155)$ & $-0.007^{* * *}$ & 0.000 & $(0.005)$ \\
\hline Non-western descendant & 0.0324 & & 0.028 & & -0.004 & -0.012 & $(0.006)^{* *}$ \\
\hline \multicolumn{8}{|l|}{ Mother characteristics } \\
\hline Age at childbirth & 30.701 & $(5.039)$ & 30.707 & $(5.143)$ & 0.006 & 0.330 & $(0.167)^{* * *}$ \\
\hline Married or cohabiting & 0.940 & & 0.929 & & $-0.011 * * *$ & 0.005 & $(0.008)$ \\
\hline Number of children & 1.781 & $(0.882)$ & 1.816 & $(0.882)$ & $0.035^{* *}$ & 0.040 & $(0.029)$ \\
\hline Work experience (years) & 6.573 & $(4.285)$ & 6.503 & $(4.221)$ & -0.070 & 0.137 & $(0.139)$ \\
\hline \multicolumn{8}{|l|}{ Income: } \\
\hline Earnings $(100,000$ DKK $)$ & 1.766 & $(1.055)$ & 1.737 & $(1.026)$ & $-0.029^{*}$ & 0.031 & $(0.034)$ \\
\hline $\begin{array}{l}\text { - missing } \\
\text { Labor market status: }\end{array}$ & 0.006 & & 0.008 & & 0.001 & 0.000 & $(0.003)$ \\
\hline Self-employed & 0.022 & & 0.022 & & 0.000 & -0.005 & $(0.005)$ \\
\hline Employee & 0.730 & & 0.735 & & 0.005 & 0.017 & $(0.014)$ \\
\hline Employee, manager & 0.138 & & 0.132 & & -0.006 & -0.007 & $(0.011)$ \\
\hline Unemployed & 0.066 & & 0.070 & & 0.004 & 0.008 & $(0.008)$ \\
\hline Inactive & 0.038 & & 0.033 & & -0.004 & -0.013 & $(0.006)^{* *}$ \\
\hline - missing & 0.006 & & 0.008 & & 0.001 & 0.000 & $(0.003)$ \\
\hline \multicolumn{8}{|l|}{ Education: } \\
\hline Basic & 0.160 & & 0.158 & & -0.002 & -0.013 & $(0.012)$ \\
\hline High school & 0.107 & & 0.106 & & -0.001 & -0.003 & $(0.010)$ \\
\hline Vocational & 0.413 & & 0.419 & & 0.005 & -0.001 & $(0.016)$ \\
\hline College & 0.304 & & 0.303 & & -0.001 & 0.017 & $(0.015)$ \\
\hline - missing & 0.016 & & 0.015 & & -0.001 & 0.000 & $(0.004)$ \\
\hline \multicolumn{8}{|l|}{ Father characteristics } \\
\hline Father non-missing & 0.994 & & 0.995 & & 0.001 & 0.000 & $(0.002)$ \\
\hline Age at childbirth & 32.820 & $(6.817)$ & 32.672 & $(6.760)$ & -0.148 & 0.191 & $(0.222)$ \\
\hline Married or cohabiting & 0.940 & & 0.930 & & $-0.010^{* *}$ & 0.006 & $(0.008)$ \\
\hline Number of children & 1.807 & $(0.953)$ & 1.831 & $(0.933)$ & 0.024 & 0.011 & $(0.031)$ \\
\hline Work experience (years) & 9.421 & $(5.704)$ & 9.281 & $(5.544)$ & -0.140 & 0.292 & $(0.184)$ \\
\hline \multicolumn{8}{|l|}{ Income: } \\
\hline Earnings $(100,000$ DKK $)$ & 2.514 & $(1.647)$ & 2.504 & $(1.608)$ & -0.010 & 0.083 & $(0.053)$ \\
\hline - missing & 0.016 & & 0.017 & & 0.001 & -0.002 & $(0.004)$ \\
\hline \multicolumn{8}{|l|}{ Labor market status: } \\
\hline Self-employed & 0.077 & & 0.075 & & -0.002 & -0.007 & $(0.009)$ \\
\hline Employee & 0.681 & & 0.677 & & -0.004 & -0.003 & $(0.015)$ \\
\hline Employee, manager & 0.164 & & 0.167 & & 0.003 & 0.018 & $(0.012)$ \\
\hline Unemployed & 0.033 & & 0.036 & & 0.003 & -0.007 & $(0.006)$ \\
\hline Inactive & 0.030 & & 0.028 & & -0.002 & 0.002 & $(0.006)$ \\
\hline - missing & 0.016 & & 0.017 & & 0.001 & -0.002 & $(0.004)$ \\
\hline \multicolumn{8}{|l|}{ Education: } \\
\hline Basic & 0.180 & & 0.170 & & -0.010 & -0.022 & $(0.012)^{*}$ \\
\hline High school & 0.076 & & 0.078 & & 0.002 & 0.003 & $(0.009)$ \\
\hline Vocational & 0.497 & & 0.506 & & 0.010 & 0.020 & $(0.016)$ \\
\hline College & 0.216 & & 0.217 & & 0.002 & 0.008 & $(0.013)$ \\
\hline - missing & 0.031 & & 0.028 & & -0.004 & -0.009 & $(0.006)^{*}$ \\
\hline Number of births & 7,345 & & 8,149 & & & & \\
\hline
\end{tabular}


Table 6: Descriptive Statistics for Leave and Outcomes

\begin{tabular}{|c|c|c|c|c|c|c|c|c|c|}
\hline \multirow[t]{2}{*}{ Date of childbirth } & \multicolumn{2}{|c|}{ Before 1 January } & \multicolumn{2}{|c|}{ After 1 January } & \multicolumn{2}{|c|}{$\begin{array}{l}\text { Test: } \\
\text { Equal means }\end{array}$} & \multicolumn{3}{|c|}{$\begin{array}{l}\text { Test: } \\
\text { Jump at the cutoff } \\
\text { date equal to zero }\end{array}$} \\
\hline & Mean & Std.dev & Mean & Std.dev & Diffe & erence & Jump & Std.err. & \\
\hline Leave & & & & & & & & & \\
\hline Maternity leave (days) & 244.074 & $(107.066)$ & 273.235 & $(82.371)$ & 29.162 & $* * *$ & 31.520 & $(3.106)$ & $* * *$ \\
\hline Paternity leave (days) & 15.817 & $(25.578)$ & 16.071 & $(26.687)$ & 0.254 & & -0.834 & $(0.857)$ & \\
\hline \multicolumn{10}{|l|}{ Child outcomes } \\
\hline \multicolumn{10}{|l|}{ Within 1 year } \\
\hline Number of hospital admissions & 0.379 & $(0.958)$ & 0.330 & $(0.908)$ & -0.049 & $* * *$ & -0.025 & $(0.031)$ & \\
\hline $\begin{array}{l}\text { Number of emergency department visits } \\
\text { Within } 3 \text { years }\end{array}$ & 0.103 & $(0.382)$ & 0.091 & $(0.337)$ & -0.013 & $* *$ & -0.003 & $(0.012)$ & \\
\hline Number of hospital admissions & 0.723 & $(1.619)$ & 0.706 & $(2.068)$ & -0.018 & & 0.023 & $(0.061)$ & \\
\hline \multirow{2}{*}{\multicolumn{9}{|c|}{ Maternal outcomes }} & \\
\hline Within 1 year & & & & & & & & & \\
\hline Number of hospital admissions & 0.159 & $(0.491)$ & 0.139 & $(0.485)$ & -0.021 & $* * *$ & -0.036 & $(0.016)$ & ** \\
\hline Number of non-birth hospital admissions & 0.146 & $(0.470)$ & 0.126 & $(0.469)$ & -0.019 & $* *$ & -0.029 & $(0.015)$ & * \\
\hline Hospitalized with depression $(0 / 1)$ & 0.009 & & 0.008 & & -0.002 & & -0.001 & $(0.003)$ & \\
\hline Receiving antidepressants $(0 / 1)$ & 0.027 & & 0.025 & & -0.002 & & -0.001 & $(0.005)$ & \\
\hline \multicolumn{10}{|l|}{ Within 3 years } \\
\hline Number of hospital admissions & 0.684 & $(1.060)$ & 0.633 & $(1.045)$ & -0.050 & $* * *$ & -0.069 & $(0.034)$ & ** \\
\hline Number of non-birth hospital admissions & 0.312 & $(0.807)$ & 0.289 & $(0.788)$ & -0.022 & * & -0.028 & $(0.026)$ & \\
\hline Hospitalized with depression $(0 / 1)$ & 0.018 & & 0.016 & & -0.002 & & -0.002 & $(0.004)$ & \\
\hline Receiving antidepressants $(0 / 1)$ & 0.068 & & 0.068 & & 0.000 & & 0.007 & $(0.008)$ & \\
\hline \multicolumn{10}{|l|}{ Family outcomes } \\
\hline Relationship dissolution $(0 / 1)$ & 0.110 & & 0.089 & & -0.021 & $* * *$ & -0.013 & $(0.010)$ & \\
\hline Having a new child $(0 / 1)$ & 0.001 & & 0.001 & & 0.000 & & -0.001 & $(0.001)$ & \\
\hline \multicolumn{10}{|l|}{ Within 3 years } \\
\hline Relationship dissolution $(0 / 1)$ & 0.170 & & 0.153 & & -0.018 & $* * *$ & -0.005 & $(0.012)$ & \\
\hline Having a new child $(0 / 1)$ & 0.258 & & 0.237 & & -0.021 & $* * *$ & -0.023 & $(0.014)$ & * \\
\hline Number of births & 7345 & & 8149 & & & & & & \\
\hline
\end{tabular}


Table 7: IV Estimates of the Effect of Increasing Maternity Leave by 100 Days

\begin{tabular}{|c|c|c|c|c|}
\hline & $\begin{array}{c}(1) \\
\text { Coef./Std.err. }\end{array}$ & $\begin{array}{c}(2) \\
\text { Coef./Std.err. }\end{array}$ & $\begin{array}{c}\text { (3) } \\
\text { Coef./Std.err. }\end{array}$ & $\begin{array}{c}\text { (4) } \\
\text { Coef./Std.err. }\end{array}$ \\
\hline \multicolumn{5}{|l|}{ Child outcomes } \\
\hline Hospital admissions & $\begin{array}{r}-0.048 \\
(0.102)\end{array}$ & $\begin{array}{r}-0.040 \\
(0.107)\end{array}$ & $\begin{array}{r}-0.019 \\
(0.105)\end{array}$ & $\begin{array}{r}-0.018 \\
(0.104)\end{array}$ \\
\hline Emergency department visits & $\begin{array}{r}-0.006 \\
(0.035)\end{array}$ & $\begin{array}{r}-0.001 \\
(0.036)\end{array}$ & $\begin{array}{r}0.003 \\
(0.036)\end{array}$ & $\begin{array}{r}0.003 \\
(0.036)\end{array}$ \\
\hline \multicolumn{5}{|l|}{ Within 3 years } \\
\hline Hospital admissions & $\begin{array}{r}0.154 \\
(0.199)\end{array}$ & $\begin{array}{r}0.185 \\
(0.208)\end{array}$ & $\begin{array}{r}0.214 \\
(0.205)\end{array}$ & $\begin{array}{r}0.216 \\
(0.203)\end{array}$ \\
\hline Emergency department visits & $\begin{array}{r}-0.100 \\
(0.088)\end{array}$ & $\begin{array}{r}-0.080 \\
(0.092)\end{array}$ & $\begin{array}{r}-0.073 \\
(0.090)\end{array}$ & $\begin{array}{r}-0.072 \\
(0.089)\end{array}$ \\
\hline \multicolumn{5}{|l|}{$\begin{array}{l}\text { Maternal outcomes } \\
\text { Within } 1 \text { year }\end{array}$} \\
\hline Hospital admissions & $\begin{array}{l}-0.114^{* *} \\
(0.052)\end{array}$ & $\begin{array}{l}-0.116^{* *} \\
(0.054)\end{array}$ & $\begin{array}{l}-0.106^{* *} \\
(0.054)\end{array}$ & $\begin{array}{l}-0.107^{* *} \\
(0.053)\end{array}$ \\
\hline Non-birth hospital admissions & $\begin{array}{l}-0.092^{*} \\
(0.049)\end{array}$ & $\begin{array}{l}-0.094^{*} \\
(0.052)\end{array}$ & $\begin{array}{l}-0.085^{*} \\
(0.051)\end{array}$ & $\begin{array}{l}-0.086^{*} \\
(0.051)\end{array}$ \\
\hline Hospitalized with depression $(0 / 1)$ & $\begin{array}{r}-0.003 \\
(0.009)\end{array}$ & $\begin{array}{r}-0.002 \\
(0.010)\end{array}$ & $\begin{array}{r}-0.002 \\
(0.010)\end{array}$ & $\begin{array}{r}-0.002 \\
(0.010)\end{array}$ \\
\hline Receiving antidepressants $(0 / 1)$ & $\begin{array}{r}-0.002 \\
(0.016)\end{array}$ & $\begin{array}{r}-0.002 \\
(0.017)\end{array}$ & $\begin{array}{r}-0.001 \\
(0.017)\end{array}$ & $\begin{array}{r}-0.001 \\
(0.017)\end{array}$ \\
\hline \multicolumn{5}{|l|}{ Within 3 years } \\
\hline Hospital admissions & $\begin{array}{l}-0.220^{* *} \\
(0.109)\end{array}$ & $\begin{array}{l}-0.199^{*} \\
(0.113)\end{array}$ & $\begin{array}{r}-0.181 \\
(0.111)\end{array}$ & $\begin{array}{l}-0.182^{*} \\
(0.111)\end{array}$ \\
\hline Non-birth hospital admissions & $\begin{array}{r}-0.089 \\
(0.083)\end{array}$ & $\begin{array}{r}-0.091 \\
(0.087)\end{array}$ & $\begin{array}{r}-0.077 \\
(0.085)\end{array}$ & $\begin{array}{r}-0.079 \\
(0.085)\end{array}$ \\
\hline Hospitalized with depression $(0 / 1)$ & $\begin{array}{r}-0.006 \\
(0.013)\end{array}$ & $\begin{array}{r}-0.006 \\
(0.014)\end{array}$ & $\begin{array}{r}-0.005 \\
(0.014)\end{array}$ & $\begin{array}{r}-0.006 \\
(0.014)\end{array}$ \\
\hline Receiving antidepressants $(0 / 1)$ & $\begin{array}{r}0.023 \\
(0.026)\end{array}$ & $\begin{array}{r}0.026 \\
(0.027)\end{array}$ & $\begin{array}{r}0.027 \\
(0.027)\end{array}$ & $\begin{array}{r}0.027 \\
(0.027)\end{array}$ \\
\hline Parental characteristics & & $\mathrm{x}$ & $\mathrm{x}$ & $\mathrm{x}$ \\
\hline Newborn characteristics & & & $\mathrm{x}$ & $\mathrm{x}$ \\
\hline Length of paternity leave & & & $\mathrm{x}$ & \\
\hline
\end{tabular}

\footnotetext{
Notes: ${ }^{\prime}{ }^{* * *},{ }_{* *},{ }^{*},{ }^{*}$ indicate statistical significance at the 1,5 , and 10 percent levels, respectively.

b) Standard errors are in parentheses. They are clustered by mother for the child outcomes.

c) All specifications include a linear function in distance, $d_{i}$, and distance interacted with an indicator for whether childbirth occurred before or after 1 January, 2002.
} 
Table 8: IV Estimates of the Effect of Increasing Maternity Leave by 100 Days on Family Outcomes

\begin{tabular}{|c|c|c|c|c|}
\hline & $(1)$ & $\overline{(2)}$ & $(3)$ & $(4)$ \\
\hline $\begin{array}{l}\text { Family outcomes } \\
\text { Within } 1 \text { year }\end{array}$ & Coef./Std.err. & Coef./Std.err. & Coef./Std.err. & Coef./Std.err. \\
\hline Relationship dissolution $(0 / 1)$ & $\begin{array}{r}-0.043 \\
(0.032)\end{array}$ & $\begin{array}{r}-0.025 \\
(0.029)\end{array}$ & $\begin{array}{r}-0.029 \\
(0.029)\end{array}$ & $\begin{array}{r}-0.027 \\
(0.029)\end{array}$ \\
\hline Having a new child $(0 / 1)$ & $\begin{array}{r}-0.002 \\
(0.004)\end{array}$ & $\begin{array}{r}-0.002 \\
(0.004)\end{array}$ & $\begin{array}{r}-0.002 \\
(0.004)\end{array}$ & $\begin{array}{r}-0.002 \\
(0.004)\end{array}$ \\
\hline Within 3 years & & & & \\
\hline Relationship dissolution $(0 / 1)$ & $\begin{array}{r}-0.015 \\
(0.039)\end{array}$ & $\begin{array}{r}0.009 \\
(0.037)\end{array}$ & $\begin{array}{r}0.003 \\
(0.037)\end{array}$ & $\begin{array}{r}0.005 \\
(0.037)\end{array}$ \\
\hline Having a new child $(0 / 1)$ & $\begin{array}{l}-0.074^{*} \\
(0.045)\end{array}$ & $\begin{array}{r}-0.059 \\
(0.045)\end{array}$ & $\begin{array}{r}-0.060 \\
(0.045)\end{array}$ & $\begin{array}{r}-0.060 \\
(0.044)\end{array}$ \\
\hline Parental characteristics & & $\mathrm{x}$ & $\mathrm{x}$ & $\mathrm{x}$ \\
\hline Newborn characteristics & & & $\mathrm{x}$ & $\mathrm{x}$ \\
\hline Length of paternity leave & & & $\mathrm{x}$ & \\
\hline
\end{tabular}
a) ${ }_{* * *},{ }^{*}{ }^{*},{ }^{\prime},{ }^{*}$ indicate statistical significance at the 1,5 , and 10 percent levels, respectively.
b) Standard errors are in parentheses.
c) All specifications include a linear function in distance, $d_{i}$, and distance interacted with an indicator for whether childbirth occurred before or after 1 January, 2002. 


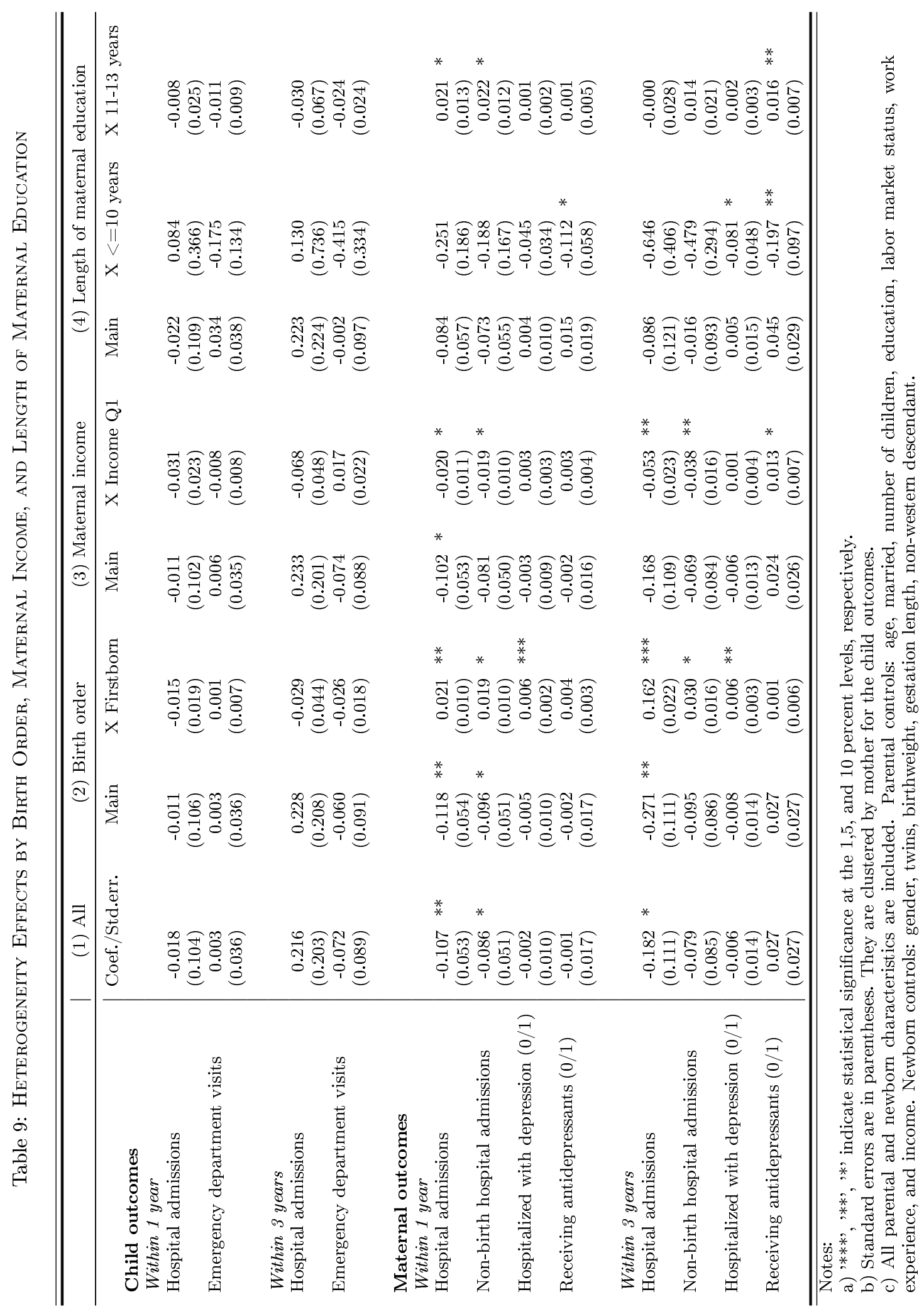

